\title{
Comparative evaluation of Amplicor HIV-1 DNA test, version 1.5, by manual and automated DNA extraction methods using venous blood and dried blood spots for HIV-1 DNA PCR testing
}

\author{
ANTHONY NSOJO ${ }^{1}$, SAID ABOUD ${ }^{1,22^{*}}$ and ELIGIUS LYAMUYA ${ }^{1}$ \\ ${ }^{1}$ Department of Microbiology and Immunology, Muhimbili University of Health and Allied Sciences, \\ P.O. Box 65001, Dar es Salaam, Tanzania \\ ${ }^{2}$ Department of Microbiology, Tumor and Cell Biology, Karolinska Institutet, Nobels väg 18, SE-171 82 \\ Solna, Stockholm, Sweden
}

\begin{abstract}
Human immunodeficiency virus (HIV) DNA polymerase chain reaction (PCR) test using venous blood sample has been used for many years in low resource settings for early infant diagnosis of HIV infection in children less than 18 months. The aim of this study was to evaluate and compare the performance characteristics of Amplicor HIV-1 DNA assay version 1.5 following processing of venous blood and dried blood spot (DBS) samples by Roche manual DNA extraction and automated Roche MagNA Pure LC instrument (MP) for HIV-1 DNA PCR testing in Dar es Salaam, Tanzania, in order to scale up early infant diagnosis of HIV infection in routine practice. Venous blood samples from children under 18 months born to HIV-infected mothers between January and April 2008 were collected. Venous blood was used to prepare cell pellet and DBS samples. DNA extractions by manual procedure and MP were performed each on cell pellet, venous blood and DBS samples and tested by Amplicor HIV-1 DNA assay. Of 325 samples included, 60 (18.5\%) were confirmed HIV-infected by manual extraction performed on cell pellets. Sensitivity of the assay following MP processing of venous blood was 95\% (95\% CI; 86.1-99.0\%) and 98.3\% (95\% CI; 91.1 to 99.9\%) for the manual extraction and processing by MP performed on DBS samples. Specificity of the assay with all DNA extraction methods was $99.6 \%$ (95\% CI; 97.9 to 100\%). Performance of the assay with Roche manual extraction and processing by MP on DBS samples compared well with Roche manual extraction performed on cell pellet samples. The choice of DNA extraction method needs to be individualized based on the level of laboratory facility, volume of testing and cost benefit analysis before it is adopted for use.
\end{abstract}

Key words: human immunodeficiency virus, DNA extraction, venous blood, dried blood spot, polymerase chain reaction

\section{Introduction}

It is estimated that 370,000 children worldwide became infected with human immunodeficiency virus (HIV) in 2007, the vast majority of them being newborns (UNAIDS, 2008). Sub Saharan Africa has remained most heavily affected by HIV accounting for $67 \%$ of all people living with HIV and for $72 \%$ of acquired immunodeficiency syndrome (AIDS) deaths. In $2007,33 \%$ of pregnant women in low and middle-income countries were offered antiretroviral therapy to prevent HIV transmission to their newborns (UNAIDS, 2008). Children born to HIVinfected mothers are usually offered services for HIV-1 DNA PCR testing and those that are found to be HIV-infected are referred to HIV and AIDS care

$2 \quad{ }^{*}$ Correspondence: Dr. Said Aboud; E-mail address: aboudsaid@yahoo.com and treatment clinics for further management. Early initiation of care and treatment to infected infants born to HIV-1 infected mothers has remained a great challenge in Africa due to lack of access to early and accurate diagnostic method. This has lead to high mortality rate in vertically HIV-1 infected infants in Africa (Newell et al., 2004).

HIV-1 DNA polymerase chain reaction (PCR) test using venous blood sample has been used in low resource settings for early infant diagnosis of HIV infection in children less than 18 months (Sherman et al., 2005). The use of venous blood sample has limitations including lack of expertise needed for venipuncture of small infants, transportation and storage at $2-25^{\circ} \mathrm{C}$, and processing within 4 days of specimen collection. Various studies in several settings, have demonstrated excellent transfer from venous blood to dried blood spot (DBS) specimen, which has the advantages 
of requiring only a few drops of blood (20-50 $\mu \mathrm{L})$ obtained from a heel prick and applied to the filter paper. Once dried, a filter paper can be stored at room temperature eliminating the need to store and transport whole blood at $2-25{ }^{\circ} \mathrm{C}$ (Fisher et al., 2004; Nyambi et al., 1994; Sherman et al., 2005; Beck et al., 2001). Use of filter papers also provides fewer chances for mislabeling though it can occur, because there are fewer transfer steps once the blood is applied to the paper. The DNA in the filter paper also remains stable for a longer time. Recently, usefulness of DBS specimens has been emphasized as a means for ensuring greater accessibility to HIV testing for the paediatric population (Stevens et al., 2008).

DNA extraction is a critical step performed before extracted DNA is amplified and detected and diagnostic accuracy of HIV DNA PCR result is key to HIV and AIDS care and treatment. Previous study done in Tanzania to evaluate the performance of the Amplicor HIV-1 DNA assay version 1.5 (Roche Molecular Systems, Branchburg, NJ, USA) using venous blood samples from pregnant women and manual DNA extraction showed sensitivity of $99.1 \%$ and specificity of $100 \%$ (Lyamuya et al., 2000). Among the most technically demanding and labor-intensive procedure in performing the HIV-1 DNA PCR testing is the nucleic acid isolation since it is still performed manually in many laboratories in resource constrained countries. Development of an automated nucleic acid extraction technology was an important achievement in resolving this problem particularly in a busy routine molecular diagnostic laboratory. Previous study done in South Africa to evaluate the diagnostic accuracy of the Amplicor HIV-1 DNA assay version 1.5 (Roche Molecular Systems, Branchburg, NJ, USA) on DNA extracted from DBS specimens using the nucleic acid purification technology MagNA Pure LC instrument (MP) (Roche Applied Science, Indianapolis, IN, USA) showed sensitivity of 98.28\% and specificity of $98.68 \%$ (Patton et al., 2007). Another study conducted in USA to evaluate the performance of Amplicor HIV-1 DNA assay version 1.5 (Roche Molecular Systems, Branchburg, NJ, USA) following automated sample processing by the MP on whole blood specimen showed an analytical sensitivity of $95 \%$ with clinical sensitivity and specificity of 100\% (Germer et al., 2006). The performance of MP has also been reported in other settings (Loeffler et al., 2002; Fiebelkorn et al., 2002; Kessler et al., 2001). Data on the performance characteristics of Amplicor HIV-1 DNA assay version 1.5 with sample processing by the MP in settings with diversity of HIV subtypes is limited. The aim of this study was to evaluate and compare the performance characteristics of Amplicor HIV1 DNA assay version 1.5 following processing of venous blood and DBS samples by Roche manual DNA extraction and automated MP for HIV-1 DNA PCR testing in Dar es Salaam, Tanzania, in order to scale up early infant diagnosis of HIV infection in routine practice.

\section{Materials and Methods}

\section{DNA assays}

Venous blood samples from children under 18 months (6 weeks to 12 months) born to HIV-infected mothers attending HIV and AIDS care and treatment clinics in Dar es Salaam, Tanzania between January and April 2008 were used for evaluation. Of one $\mathrm{mL}$ of venous blood collected, $500 \mu \mathrm{L}$ was used to prepare peripheral blood mononuclear cells (PBMC) or cell pellet for Roche manual DNA extraction and $200 \mu \mathrm{L}$ for automated DNA extraction by MP (Roche Applied Science, Indianapolis, IN, USA). Amplicor HIV-1 DNA assay version 1.5 (Roche Molecular Systems, Inc., Branchburg, NJ, USA) reagents were used for Roche manual DNA extraction on cell pellet. Briefly, one $\mathrm{mL}$ of Roche blood wash solution was added to appropriate number of $2 \mathrm{~mL}$ screw cap tubes. The venous blood sample was inverted 10-15 times to mix thoroughly, and $500 \mu \mathrm{L}$ were pipetted into a tube containing specimen wash solution, tightly caped, labeled and vortexed for 10 seconds, and incubated for 5 minutes at room temperature. The tubes were then centrifuged at $20800 \mathrm{x}$ g for 3 minutes. Using a fine-tipped transfer pipette, the supernatant was aspirated carefully not to disturb the cell pellet. Similar procedure was repeated three times to give deposition of PBMC or cell pellets at the bottom of the tubes. The PBMC or cell pellets were stored at $-80^{\circ} \mathrm{C}$ freezer until the time for DNA extraction.

Remaining venous blood sample was used to prepare five $20 \mu \mathrm{L}$ blood spots on filter papers (Schleicher \& Schuell, S\&S grade 903, Dassel, Germany). Briefly, the blood spots were placed on a horizontal drying rack to air dry for at least 3 hours to overnight to obtain DBS samples, avoiding direct sun light, dust, bugs and contacts between cards. Each DBS card was then stored in separate glassine envelope and then every 10 of them were put into a zip lock plastic bag with desiccant packages. A humidity indicator card was added in a bag, air was removed, sealed and kept at room temperature until time for DNA extraction. DNA extractions by 
Roche manual procedure and MP (Roche Applied Science, Indianapolis, IN, USA) were performed each on cell pellet, venous blood and DBS sample as used previously (Lyamuya et al., 2000; Sherma et al., 2005; Patton et al., 2007; Germer et al., 2006). Each DNA extract was amplified and tested by Amplicor HIV-1 DNA assay version 1.5 assay (Roche Molecular Systems, Branchburg, NJ, USA). Three negative and one positive controls were included in each HIV DNA PCR assay run as per manufacturer's instructions. Known Virology Quality Assurance (VQA) proficiency testing panel pellets were included in every assay run. All assay runs were validated to ensure accuracy and reliability of results.

\section{Ethical considerations}

The study was carried out in line with existing ethical guidelines. Ethical approval was obtained from the Research and Publications Committee of Muhimbili University of Health and Allied Sciences. Written informed consent was obtained from parent/guardian prior to the enrolment of the child into the study. Children found to be HIVinfected were referred to care and treatment centers for further management according to national guidelines.

\section{Statistical analysis}

Roche Amplicor HIV-1 DNA assay version 1.5 with Roche manual DNA extraction performed on cell pellet sample was used as a reference method. Epi $\mathrm{Info}^{\mathrm{TM}}$ program version 6.7 was used for analysis. Sensitivity, specificity, PPV and NPV with 95\% confidence intervals (CI) for the Amplicor HIV-1 DNA assay version 1.5 were calculated by each of the DNA extraction method evaluated. Operational characteristics of the Amplicor HIV-1 DNA assay version 1.5 by DNA extraction methods which included amount of blood required, total DNA extraction time, total hands on time for extraction, throughput and appraisal by testing personnel were compared and assessed among the DNA extraction methods.

\section{Results}

Three hundred and twenty five children samples were included in the study. The mean age of children was 5 months ( 3 weeks to 12 months). Many children $(46.8 \%)$ were in the 0-3 months of age. Sixty (18.5\%) samples were confirmed HIV-infected by the Roche Amplicor HIV-1 DNA assay version 1.5 with Roche manual DNA extraction performed on cell pellet. Of these children samples, $23(15.1 \%)$ were from 0-3 months, 11 (19.3\%) from 4-6 months, 7 (20.6\%) from 7-9 months and 17 (25\%) from 1012 months of age.

The sensitivity, specificity, positive predictive value (PPV) and negative predictive value (NPV) of the Amplicor HIV-1 DNA assay version 1.5 by Roche manual DNA extraction and processing by the MP are summarized in Table 1. The sensitivity of the assay following MP processing of venous blood was $95 \%$ (95\% CI; 86.1-99.0\%) and $98.3 \%$ (95\% CI; 91.1 to $99.9 \%$ ) for the Roche manual DNA extraction and processing by the MP performed on DBS sample. The specificity of the assay with all DNA extraction methods was $99.6 \%$ (95\% CI; 97.9 to $100 \%$ ). The Amplicor HIV-1 DNA assay version 1.5 following Roche manual DNA extraction and processing by the MP performed on DBS specimens revealed similar sensitivity, specificity, PPV and NPV. When the prevalence of HIV-infected children was $15.1 \%$, the PPV and NPV of the assay with all DNA extraction methods were $95.7 \%$ and $99.2 \%$, respectively, except for venous blood processing by the MP which had NPV of $98.5 \%$. At the highest prevalence of $25 \%$, the PPV and NPV of the assay with all DNA extraction methods were $100 \%$ except for venous blood processing by the MP which had NPV of $98.7 \%$.

Table 1: The sensitivity, specificity, PPV and NPV of Amplicor HIV-1 DNA assay version 1.5, by DNA extraction methods

\begin{tabular}{|c|c|c|c|}
\hline $\begin{array}{l}\text { P e r f o r m a n c e } \\
\text { characteristic }\end{array}$ & $\begin{array}{l}\text { Automated DNA extraction } \\
\text { on venous blood samples by } \\
\text { the MP } \\
\text { No. of samples } \\
\%(95 \% \mathrm{CI})\end{array}$ & $\begin{array}{l}\text { Roche manual DNA } \\
\text { extraction on DBS samples } \\
\text { No. of samples } \\
\%(95 \% \text { CI })\end{array}$ & $\begin{array}{l}\text { Automated DNA extraction on } \\
\text { DBS samples by the MP } \\
\text { No. of samples } \\
\%(95 \% \text { CI })\end{array}$ \\
\hline Sensitivity $(n=60)$ & $95(86.08-98.96 \%)$ & $\begin{array}{l}59 \\
98.3(91.06-99.96 \%)\end{array}$ & $\begin{array}{l}59 \\
98.3(91.06-99.96 \%)\end{array}$ \\
\hline Specificity $(n=265)$ & $\begin{array}{l}264 \\
99.6(97.92-99.99 \%)\end{array}$ & $\begin{array}{l}264 \\
99.6(97.92-99.99 \%)\end{array}$ & $\begin{array}{l}264 \\
99.6(97.92-99.99 \%)\end{array}$ \\
\hline
\end{tabular}




\begin{tabular}{|c|c|c|c|}
\hline $\begin{array}{l}\text { P e r f o r m a n c e } \\
\text { characteristic }\end{array}$ & $\begin{array}{l}\text { Automated DNA extraction } \\
\text { on venous blood samples by } \\
\text { the MP } \\
\text { No. of samples } \\
\%(95 \% \mathrm{CI})\end{array}$ & $\begin{array}{l}\text { Roche manual DNA } \\
\text { extraction on DBS samples } \\
\text { No. of samples } \\
\%(95 \% \text { CI })\end{array}$ & $\begin{array}{l}\text { Automated DNA extraction on } \\
\text { DBS samples by the MP } \\
\text { No. of samples } \\
\%(95 \% \mathrm{CI})\end{array}$ \\
\hline PPV $(n=60)$ & $98.3(90.76-99.96)$ & $\begin{array}{l}59 \\
98.3(91.06-99.96 \%)\end{array}$ & $\begin{array}{l}59 \\
98.3(91.06-99.96 \%)\end{array}$ \\
\hline $\operatorname{NPV}(n=265)$ & $\begin{array}{l}262 \\
98.9(96.75-99.77 \%)\end{array}$ & $\begin{array}{l}265 \\
99.6(97.92-99.99 \%)\end{array}$ & $\begin{array}{l}265 \\
99.6(97.92-99.99 \%)\end{array}$ \\
\hline
\end{tabular}

PPV, positive predictive value; NPV, negative predictive value; DBS, dried blood spot; MP, MagNA Pure LC instrument

The Amplicor HIV-1 DNA assay version 1.5 following Roche manual DNA extraction and processing by the MP performed on venous blood and DBS samples had variable operational DNA extraction characteristics. The Amplicor HIV-1 DNA assay version 1.5 with Roche manual DNA extraction performed on DBS sample required 20$50 \mu \mathrm{L}$ of blood compared to $500-1000 \mu \mathrm{L}, 200 \mu \mathrm{L}$ and $50 \mu \mathrm{L}$ for manual extraction on cell pellets, processing of venous blood and DBS specimens by the MP, respectively. Processing of venous blood by the MP required 90 and 10 minutes of total extraction time and hands on time for extraction, respectively. The Amplicor HIV-1 DNA assay version 1.5 with the four DNA extraction methods showed variable throughputs, 32 samples/hour being for processing of either venous blood or DBS specimens by the MP. Cost per the Amplicor HIV-1 DNA assay version 1.5 following automated sample processing by the MP was more expensive (18 vs. 15 USD) compared to the Roche manual DNA extraction. The Amplicor HIV-1 DNA assay version 1.5 following automated processing of venous blood by the MP was appraised as very easy to perform.

\section{Discussion}

The study aimed to evaluate and compare the performance characteristics of the Amplicor HIV1 DNA assay version 1.5 following processing of venous blood and DBS samples by Roche manual DNA extraction and automated MP for HIV-1 DNA PCR testing for early infant diagnosis of HIV infection in Dar es salaam, Tanzania. Study findings showed that the sensitivity of the assay following MP processing of venous blood samples was $95 \%$ and $98.3 \%$ (95\% CI; 91.1 to $99.9 \%$ ) for the Roche manual extraction and processing by the MP performed on DBS samples. Specificity of the assay with all DNA extraction methods was $99.6 \%$ (95\% CI; 97.9 to $100 \%$ ).

The study showed that the sensitivity of the assay following the MP processing of venous blood was $95 \%$ (95\% CI; 86.1-99.0\%). The sensitivity for both Roche manual extraction and processing by the MP performed on DBS sample was $98.3 \%$. Three specimens tested initially false negative by the Amplicor HIV-1 DNA assay version 1.5 following the MP processing of venous blood, one of these being false negative to both Roche manual extraction and processing by the MP performed on DBS samples. It can not be excluded that the initial false negative results obtained when testing was due to a technical error. Repeat testing was possible for Roche manual extraction and processing by the MP performed on DBS sample but did not improve the sensitivity to $100 \%$. Repeat testing for automated DNA extraction using venous blood was not possible due to insufficient sample at the time of testing and it was not possible to trace the infant for repeat blood draw. Persistence of false negative results following processing of DBS and venous blood samples by the MP has been previously reported by other studies (Patton et al., 2007; Schuurman et al., 2005). The study showed that the specificity of the assay with all DNA extraction methods was $99.6 \%$ (95\% CI; 97.9 to $100 \%$ ).

Our study findings compare with findings reported from the previous studies (Fisher et al., 2004; Nyambi et al., 1994; Sherman et al., 2005; Beck et al., 2001; Patton et al., 2007). In Rwanda, where HIV subtype A is predominant, Fischer et al compared the performance of Amplicor HIV1 DNA assay version 1.5 on heel stick DBS to PBMCs using manual DNA extraction method for HIV-1 DNA PCR diagnosis in children born to HIV infected mothers, and showed sensitivity of $100 \%$ and specificity of $98 \%$ (Fisher et al., 2004). In their study DNA extraction method used Chelex-100 resin which is too labour intensive compared to the manual and automated DNA extraction methods used in our study. In Kenya, Nyambi et al showed a sensitivity of $95 \%-100 \%$ and a specificity of $100 \%$ from heel stick DBS (Nyambi et al., 1994). However, manual 
DNA extraction method was used followed by an inhouse nested PCR testing to detect HIV-1 proviral DNA. In South Africa, Sherman et al showed that the Amplicor HIV-1 DNA assay version 1.5 had a sensitivity of $100 \%$ and a specificity of $99.6 \%$ using manual DNA extraction on DBS collected on Whatman no. 1 filter paper from 288 infants born to HIV infected mothers compared with venous blood manual DNA extraction for the diagnosis of HIV infection on HIV-1 DNA PCR (Sherman et al., 2005). Patton et al showed the sensitivity of $98.28 \%$ and specificity of $98.68 \%$ of the Amplicor HIV-1 DNA assay version 1.5 on DNA extracted from pediatric heel prick DBS by the MP (Patton et al., 2007). In USA, following the MP processing of venous blood specimens from healthy blood donors and HIV-1 seropositive patients, the Amplicor HIV1 DNA assay version 1.5 showed an analytical sensitivity ( $95 \%$ detection rate) of $66.3 \%$ copies $/ \mathrm{mL}$ (Germer et al. 2006). However, in the current study, plasma HIV-1 RNA levels were not determined. HIV-1 subtypes A, C, D and circulating recombinant forms are prevalent subtypes in Tanzania (Arroyo et al., 2004; Kiwelu et al., 2003; Renjifo et al., 1998).

The costs of DBS collection kit and transportation altogether were higher ( 2 vs. 3 USD) than those of venous blood sample. Comparison of operational characteristics of Amplicor HIV-1 DNA assay version 1.5 with different DNA extraction methods showed that processing of venous blood sample by the MP is the best alternative in a high volume testing laboratory such as Zonal/National hospital as it required about 10 minutes of hands on extraction time for processing 32 samples. However, the cost per assay excluding the initial investment on the MP $(75,000$ USD) was higher and although it required $200 \mu \mathrm{L}$ of venous blood, it shared other venous blood specimen setbacks regarding collection, transportation and storage conditions. Processing of DBS specimen by the MP was laborintensive and time-consuming for excising the blood spots (Stevens et al., 2008) and required 45 minutes of hands on DNA extraction time. It also required 20-50 $\mu \mathrm{L}$ of blood (Fisher et al., 2004; Nyambi et al., 1994; Sherman et al., 2005; Beck et al., 2001) and equally expensive to processing of venous blood sample by the MP. Manual DNA extraction on DBS samples is labour-intensive and prone to crosscontamination in high-volume testing laboratory contrary to the processing of DBS sample by the MP. Difficulties in testing DBS specimens especially in high-volume testing laboratories have been described previously (Stevens et al., 2008). Manual processing of DBS samples had the advantage of being cheaper, it also required about $20 \mu \mathrm{L}$ of blood but required the longest hands on time $(133 \mathrm{~min})$ for DNA extraction. The use of an automated punch system should significantly improve the efficiency of DBS specimen processing although there is a need for further validation of a system (Stevens et al., 2008). Automated DNA extraction by the MP had the advantages of high sensitivity and specificity, high throughput in high volume testing laboratories such as Zonal/National Hospital and its feasibility in resource-limited countries but limited by higher costs including the initial investment and preventive maintenance. In South Africa where demand for HIV DNA PCR testing is high, the MP results have shown good correlation with Roche manual extraction procedure on cell pellets prepared from venous blood specimens (Sherman et al., 2005). In settings with limited initial investment, reagent rental program is an alternative way to acquire the instrument based on the volume of samples in the testing laboratory. Thus, the choice of DNA extraction method should be determined by the level of laboratory facility. Cost benefit analysis is also important to make informed decision on the choice of DNA extraction method to be adopted. One study limitation is the fact that limited amount of venous blood collected from children hindered viral load testing for quantification of plasma HIV-1 RNA levels.

In conclusion, the performance of the assay with Roche manual extraction and processing by the MP on DBS sample compared well with Roche manual extraction performed on cell pellet sample. The choice of DNA extraction method needs to be individualized based on the level of laboratory facility, volume of testing and cost benefit analysis before it is adopted for use.

\section{Acknowledgements}

We would like to acknowledge the mothers/ guardians of children whose specimens were used in the evaluation; Edna Mgimba, Ezekiel Marandu, Joha Juma and Dotto Kalovya for processing and testing of sample. Clinton Foundation Tanzania and MUHAS/Dar es Salaam City/Harvard School of Public Health (MDH) HIV and AIDS care and treatment program supported this work.

\footnotetext{
Received 14 June 2010

Revised 18 September 2010

Accepted 21 September 2010
} 


\section{References}

Arroyo, M.A., Hoelscher, M., Sanders-Buell, E., Herbinger, K.H., Samky, E., Maboko, L., Hoffmann, O., Robb, M.R., Birx, D.L., McCutchan, F.E. (2004) HIV type I subtypes among blood donors in the Mbeya region of Southwest Tanzania. AIDS Research and Human Retroviruses 20, 895-901.

Beck, I.A., Drennan, K.D., Melvin, A.J., Mohan, K.M., Herz, A.M., Alarcon, J., Piscoya, J., Velaquez, C., Frenkel, L.M. (2001) Simple, sensitive, and specific detection of human immunodeficiency virus type 1 subtype B DNA in dried blood samples for diagnosis in infants in the field. Journal of Clinical Microbiology 39, 29-33.

Fiebelkorn, K.R., Lee, B.G., Hill, C.E., Caliendo, A.M., Nolte, F.S. (2002) Clinical evaluation of an automated nucleic acid isolation system. Clinical Chemistry 48, 1613-1615.

Fischer, A., Lejczak, C., Lambert, C., Servais, J., Makombe, N., Rusine, J., Staub, T., Hemmer, R., Schneider, F., Schmit, J.C., Arendt, V. (2004) Simple DNA extraction method for dried blood spots and comparison of two PCR Assays for diagnosis of vertical human immunodeficiency virus 1 transmission in Rwanda. Journal of Clinical Microbiology 42, 16-20.

Germer, J.J., Gerads, T.M., Mandrekar, J.N., Mitchell, P.S. \& Yao, J.D. (2006) Detection of HIV-1 proviral DNA with the AMPLICOR HIV-1 DNA Test, version 1.5, following sample processing by the MagNA Pure LC instrument. Journal of Clinical Virology 37, 195-198.

Kessler, H.H., Muhlbauer, G., Stelzl, E., Daghofer, E., Santner, B.I. \& Marth, E. (2001) Fully automated nucleic acid extraction: MagNA Pure LC. Clinical Chemistry 47, 1124-1126.

Kiwelu, I.E., Renjifo, B., Chaplin, B., Sam, N., Nkya, W.M., Shao, J., Kapiga, S. \& Essex, M. (2003) HIV type 1 subtypes among bar and hotel workers in Moshi, Tanzania. AIDS Research and Human Retroviruses 19, 5764.

Loeffler, J., Schmidt, K., Hebart, H., Schumacher, U. \& Einsele, H. (2002) Automated extraction of genomic DNA from medically important yeast species and filamentous fungi by using the MagNA Pure LC system. Journal of Clinical Microbiology 40, 2240-2243.

Lyamuya, E., Olausson-Hansson, E., Albert, J.,
Mhalu, F. \& Biberfeld, G. (2000) Evaluation of a prototype Amplicor PCR assay for detection of human immunodeficiency virus type 1 DNA in blood samples from Tanzanian adults infected with HIV-1 subtypes A, C and D. Journal of Clinical Virology 17, 57-63.

Newell, M.L., Coovadia, H., Cortina-Borja, M., Rollins, N., Gaillard, P., Dabis, F., Ghent International AIDS Society (IAS) Working Group on HIV Infection in Women and Children (2004) Mortality of infected and uninfected infants born to HIV-infected mothers in Africa: a pooled analysis. Lancet 364, 1236-1243.

Nyambi, P., Fransen, K., De Beenhouwer, E.N., Chomba. E.N., Temmerman, M., NdinyaAchola, J.,Piot, P. \& van der Groen, G. (1994). Detection of human immunodeficiency virus type 1 (HIV-1) in heel prick blood on filter paper from children born to HIV1-seropositive mothers. Journal of Clinical Microbiology 32, 2858-2860.

Patton, J.C., Akkers, E., Coovadia, A.H., Meyers, T.M., Stevens, W.S. \& Sherman, G.G. (2007) Evaluation of dried whole blood spots obtained by heel or finger stick as an alternative to venous blood for diagnosis of human immunodeficiency virus type 1 Infection in vertically exposed infants in the routine diagnostic laboratory. Clinical \& Vaccine Immunology 14, 201-203.

Renjifo, B., Chaplin, B., Mwakagile, D., Shah, P., Vannberg, F., Msamanga, G., Hunter, D., Fawzi, W. \& Essex, M. (1998) Epidemic expansion of HIV type 1 subtype $\mathrm{C}$ and recombinant genotypes in Tanzania. AIDS Research and Human Retroviruses 14, 635637.

Schuurman, T., van Breda, A., de Boer, R., KooistraSmid, M., Beld, M., Savelkoul, P. \& Boom, R. (2005) Reduced PCR sensitivity due to impaired DNA recovery with the MagNA Pure LC total nucleic acid isolation kit. Journal of Clinical Microbiology 43, 46164622.

Sherman, G.G., Cooper, P.A., Coovadia, A.H., Puren, A.J., Jones, S.A., Mokhachane, M. \& Bolton, K.D. (2005) Polymerase chain reaction for diagnosis of human immunodeficiency virus infection in infancy in low resource settings. Pediatric Infectious Disease Journal 24, 993-997.

Sherman, G.G., Stevens, G., Jones, S.A., Horsfield, 
P. \& Stevens, W.S. (2005) Dried blood spots improve access to HIV diagnosis and care for infants in low-resource settings. Journal of Acquired Immune Deficiency Syndrome 38, 615-617.

Stevens, W., Sherman, G., Downing, R., Parsons, L.M., Ou, C.Y., Crowley, S., Gershy-Damet, G.M., Fransen, K., Bulterys, M., Lu, L., Homsy, J., Finkbeiner, T. \& Nkengasong, J.N. (2008) Role of laboratory in ensuring global access to ARV treatment for HIVinfected children : consensus statement on the performance of laboratory assays for early infant diagnosis. Open AIDS Journal $2: 17-25$

Tapia, N., Franco, S., Puig-Basagoiti, F., Menendez, C., Alonso, P.L., Mshinda, H., Clotet, B., Saiz, J.C. \& Martinez, M.A. (2003) Influence of human immunodeficiency virus type 1 subtype on mother-to-child transmission. Journal of General Virology 84, 607-613.

UNAIDS (2008) Report on the Global AIDS Epidemic. At http://www.unaids. org/en/KnowledgeCentre/HIVData/ GobalReport/2008/2008_Global_report. asp 